\title{
PHOTOPAROXYSMAL RESPONSES
}

\author{
MAURO MUSZKAT* - ROSANA M. GUIMARAES * - ADEMIR B. DA SILVA * \\ CARLOS J. REIS DE CAMPOS *
}

SUMMARY - Sixty-five outpatients with photoparoxysmal response (PPR) during routine EEG were studied. The PPR showed prevalence in women (75.4\%). Seizures were found in $66.1 \%$ of cases. The rest recordings were abnormal in $41.8 \%$ with prevalence of generalized paroxysm. Eight patterns of PPR were observed, being polyspike mixed to slow wave the most frequent (53\%). The epileptic group showed a bimodal distribution in the several bands of photic stimulation, near 8 and $20-24 \mathrm{~Hz}$. A sustained paroxysmal abnormality persisting after the photic stimulation was present in 6 epileptic patients.

\section{Kesposta lotoparoxistica.}

Foram estudados 65 pacientes đe ambulatório que apresentaram resposta fotoparoxistica (RF) no EEG intercritico. Houve predomínio da RF no sexo feminino $(75,4 \%)$ e $61,1 \%$ dos casos tinham hístória de crises epiléptícas. Dos 8 yadrōes de RF observados, o padrão

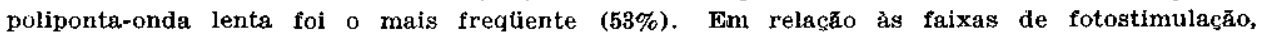
o grupo epiléptico apresentou distribuição bimodal (8 e 20-24 Hz). Os autores discutem seus achados em relaçăo aos descritos na literatura.

The relationship between epilepsy and visual stimulation has been reported since the end of last century. The first reference to photosensitive epilepsy was made by Gowers (1883), who described two patients presenting seizures when exposed to bright light 8 . There followed references by Radovicci (1932)16, Cobb (1947)2, Bickford et al. (1952)1. More recently the papers from Jeavons \& Harding 10 and Gastaut et al.7 described the most important clinical and electroencephalographic aspects of the photosensitive epilepsy. Two concepts encompass the relationship between light and epilepsy: (1) protosensitivity - abnormal response to the visual stimulation observed in laboratory, not necessarily associated to seizures; it probably represents a susceptibility pattern, genetically determined 9,20 ; the photosensitivity can be found in roughly $3 \%$ of patients who underwent a routine EEG recording 11,15; (2) photosensitive epilepsy - it includes the cases of patients with seizures and photosensitivity. According to Jeavons 9 and Jeavons \& Harding 10 the photosensitive epilepsy can be distinguished in two forms; a. pure photosensitive epilepsy - it is a relative common form of reflex epilepsy, where the seizures are triggered only by visual stimulation of the retina 3 ; its most common type is the so-called «television epilepsy» 6,18; b. epilepsy with photosensitivity - it includes the cases of patients with seizures not related to light stimulation, but with photosensitivity in electroencephalographic studies 9,20. The diagnosis of photosensitivity is made by the presence of «photoparoxysmal response» (PPR) in intermittent photic stimulation on the EEG recordings. The PPR consists of generalized discharge recorded in all regions of the scalp during intermittent photic stimulation. Usually, it consists of spike and wave and polyspike and wave complexes. The localized response in anterior (photomyoclonic response) and posterior regions (photic driving) are considered «physiological» and are excluded

* Setor de Investigaçăo e Tratamento das Epilepsias e Setor de Eletrencefalografia, Departamento de Neurologia e Neurocirungia, Escola Paulista de Medicina. This paper was supported in part by grants from CNPq. 
from the concept of PPR 12,19. The photosensitivity is genetically determined, frequently related to familiar trait, with clear prevalence in women 6,10,15. Doose et al.3 and Doose \& Gerken 4 reported that the PPR can be linked to susceptibility to develop «centrencephalic seizures». Gastaut et al.6 considered that the PPR is frequently limited to patients with «subcortical primary epilepsy», observing this response patterns, in $40 \%$ of «petit mal» cases and $20 \%$ of «grand mal» cases. Wilkins et al.20,21 found PPR frequently associated to "generalized primary epilepsy». Although uncommon, the PPR can be found in patients without epilepsy, in cases of migraine, hysteria, anxiety, toxic and metabolic states $\mathbf{1 2 , 1 3 , 1 9}$.

The purpose of this paper is to report the study on graphic-elements that compose the PPR, as well as analyzing them in epileptic and non-epileptic groups.

\section{MATERIAL AND METHOD}

Sixty-five outpatients seen at the Neurology Department, Escola Paulista de Medicina, were selected when photic stimulation induced PPR during routine EEG. All the patients had standard EEG recordings done using a 8-channel Grass Model EEG Machine. Electrodes were attached to the scalp according to the 10-20 system of the International Federation. Photic stimulation was applied to all the patients in the frequency of $6,8,16,20,24.4 z$ in addition to mixed frequency. Clinical and EEG data were collected. The EEG data 1nclude: (a) background activity; (b) resting paroxysmal changes; (c) morphologic analysis of PPR.

\section{RESULTS}

A. Clinical data: The PPR showed clear prevalence in women (75.4\%). The average age was $13.5 \pm 11$ year, ranging from 1 to 69 years. Sei\%ures were found in $66.1 \%$ of cases $(n=-43)$ and the remaining 22 were distributed into the paroxysmal non-epileptic disturbance ( $n=-10$ ) including migraine, dizziness, syncope; and other disturbances ( $n=12$ ) including stroke, behavioral disorders and metabolic states. The distribution of seizure type found in 43 patients is shown in table 1 . It can be easily seen a clear vrevalence of the tonic-clonic type $(62.8 \%)$. The pure photosensitive epilepsy was found in just one case, in which the seizures were triggered when the patient was watching television.

B. Electroencephalographic data:

1. Background activity - In 54 cases the background activity was nornal. In 11 cases it was not possible to record the background activity, because recordings were carried-eut during sleep. No change was observed in background activity after internittent photic stimulation (befure: $9.83 \pm 1.10 \mathrm{~Hz}$; after: $9.56 \pm 1,60 \mathrm{~Hz}$ ).

2. Resting paroxysmal abnormality - The rest recordings were normal in 38 cases (58.2\%). In 27 cases a prevalence of generalized paroxysm was observed, characterized by slow spike-wave, spike and polyspikes complexes (Table 2).

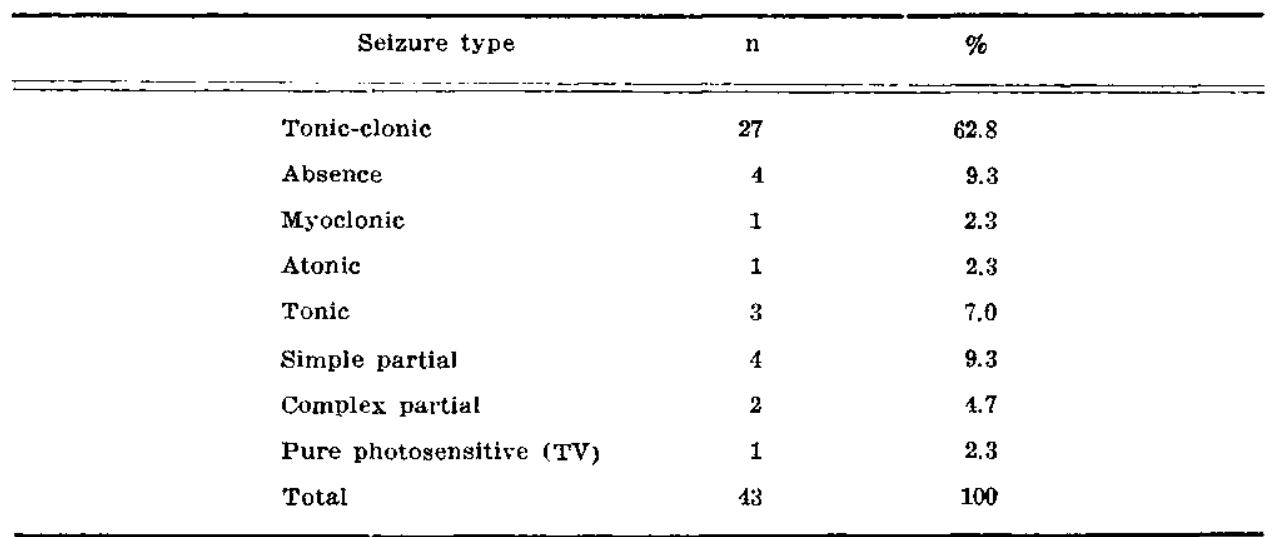


Spike-wave slow complex $(<2.5 \mathrm{~Hz})$

5

Diffuse spike

Polyspike wave

Irregular spike-wave

3

Spike-wave complex (3 Hz)

3

Temporal spike

Slow wave

Multifocal spike

Rolandic spike

Total

Table 2 - Interictal EEG changes. n, number of cases.

3. Morphologic analysis of PPR - Eight patterns of PPR were observed (in frequency order): (1) polyspike mixed to slow wave, 55.3\%; (2) polyspike, 26.1\%; (3) spike-wave complex, 20\%; (4) spike, 20\%; (5) spike and slow wave, 16\%: (6) irregular spike-wave, $12.3 \%$; (7) polyspike-wave complex, 13.8\%; (8) rhythmic slow-wave, 9\%. In 50 cases (76.9\%) association of patterns was observed. The most frequent association was the «1» with «2» patterns $(n=-44)$. The «2» pattern prevalled in $8 \mathrm{~Hz}$ band of photic stimulation, whereas other patterns were more frequent in 16 to $24 \mathrm{~Hz}$. The «2» pattern showed in average 4 to 6 spikes for each complex.

4. Epileptic $\mathrm{x}$ non-epileptic group - A comparison between epileptic and non-epileptic group showed a closer homogeneity in the several bands of photic stimulation in non-epileptic patients, whereas in epileptic group a bimodal near 8 and 20-24 Hz was observed (Fig. 1). Both groups showed similar distribution in relation to EEG patterns, with prevailing of 1 pattern. Nevertheless, the polyspike-wave complex pattern was observed unly in epileptic patients. A sustained paroxysmal abnormality persisting after the intermittent photic stimulation («after-discharge») was present in 6 cases $(9.2 \%)$, all of them from epileptic group.

\section{COMMENTS}

The prevalence of PPR in women and the average age of patients found in our paper is similar to literature data, although their causes are still unknown 9-11. One factor probably related is the oscilating level of estrogen 9 . Jeavons \& Harding 10 reported cases where the PPR was associated to menstrual cycle phases.

We have found a larger frequency of PPR (33.4\%) in non-epileptic group than the reported in literature $(3 \%)$. We ascribed this finding to our sample selection, where the EEG was performed in patients showing signs of central nervous system abnormalities, whereas in the literature the data are generally obtained from routine EEG recordings with a general population sample. Gastaut 6 found PPR in $40 \%$ of patients with absence seizures and in $20 \%$ of patients with tonic clonic seizures. Doose \& Jerkin 4 and Jeavons \& Harding 10 found clear trend to photosensitive epilepsy in nomozygotic twins, and Newmark \& Penry 15 reported familial history of epilepsy in 25 to $39 \%$ of protosensitive patients. Takahashi 19 points out the prevailing of PPR in generalized primary epilepsy.

Few papers described the EEG aspects of PPR 12,13. Spike-wave and the polyspike-wave mixed with slow wave are the most common pattern found 15. Difference; between epileptic and non-epileptic patients were not found in specialized literature, except in reference to EEG response duration. Reilly \& Peters 17 considered that the prolonged after-discharge beyond the photostimulation period suggest epilepsy, 


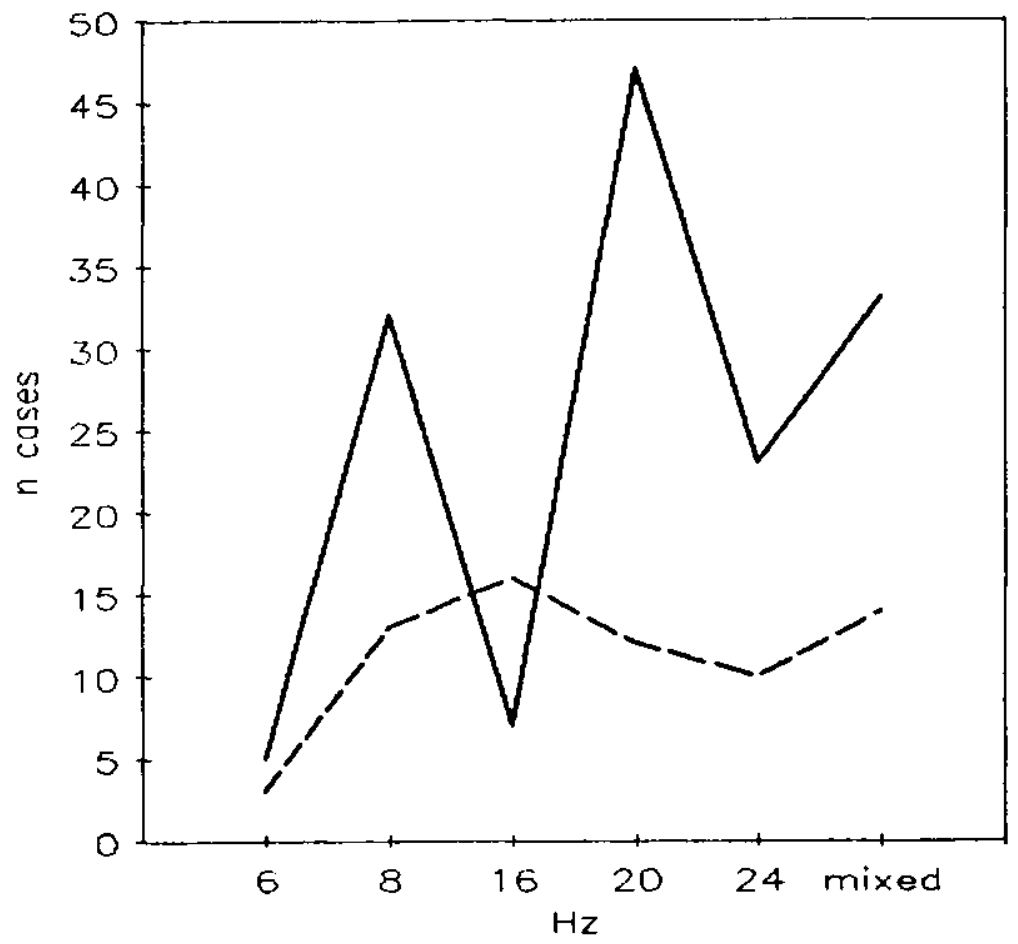

Fig. 1 - Cases distribution $\times$ photostimulation frequency. Legend: epileptics; ..... non epileptics.

since the authors found it in $90 \%$ of photosensitive epileptic patients. In our series, the after-discharge was found in only 6 epileptic cases $(9.2 \%)$.

The polyspike-wave complex found only in epileptics can suggest that in photosensitive epileptic patients there is a prevalence of the excitatory component of the complex (the polyspike) over the inhibitory (slow wave). However, for its better comprehension such supposition demand further prospective study of neurophysiological nature.

\section{REFERENCES}

1. Bickford RG, Sem-Jacobsen CW, white PT, Daly D - Some observations on the mechanisms of photic and photo-metrazol activation. Electroenceph Clin Neurophysiol $4: 275,1952$.

2. Cobb $\mathbf{S}-$ Photic driving as a cause of clinical seizures in epileptic patients. Arch Neurol Psych 58:70, 1947.

3. Doose H, Gerken H, Hien-Volpel KF, Volzke E - Genetics of photosengitive epilepsy. Neuropediat 1:56, 1962.

4. Doose $\mathbf{H}$, Gerken $\mathbf{H}$ - On the genetics of EEG-abnormalities in childhood: IV. Photoconvulsive reaction. Neuropediat 4:162, 1973.

5. Gastaut H, Broughton $\mathrm{R}$ - Crises epilépticas: fisiopatologia y clínica. In Gastaut $H$, Broughton R: Ataques Epilépticos. Toray, Barcelona, 1975.

6. Gastaut H, Regis H, Bosten $F$ - Attacks provoked by television and their mechanism. Epilepsia 3:438, 1962. 
7. Gastaut H, Trevisan C, Naquet $R$ - Diagnostic value of electroencephalographlc abnormalities provoked by intermittent photic stimulation. Electroenceph Clin Neurophysiol 10:194, 1978.

8. Gowers W - De l'Epllepsie. Masson, Paris, 1883.

9. Jeavons PM - The use photic stimulation in clniical electroencephalography. Proc Electrophysiol Technol Ass 16:225, 1969.

10. Jeavons PM, Harding GFA - Photosensitive epilepsy: a review of the literature and a study of 460 patients. Clin Dev Med 56:31, 1975.

11. Jeavons PM, Harding GFA - Photosensitive epilepsy: part two. In Laidlaw J, Richens A (eds): A Textbook of Epilepsy. Churchil Livingstone, Edinburgh, 1982, pg 195.

12. Kooi KA, Tucker RP, Marshal RE - Fundamentals of Electroencephalography (Cap 6: Cerebral reactions to stimulation). Harper \& Row, New York, 1978.

13. Kooi KA, Tucker RP, Marshal RE - Fundamentals of Electroencephalography (Cap 8: Electrographic signs of cerebral disorders). Harper \& Rox, New York, 1978.

14. Naquet R, Meldrum BS - Photogenic seizures in Baboon. In Purpura DP, Penry JK, Tower D, Woodbury DM, Walter $\mathbf{R}$ (eds): Experimental Models of Epilepsy: a Manual for the Ialoratory Worker. Raven Press, New York, 1972, pg 375.

15. Newmark M, Penry $\mathrm{K}$ - Photosensitfvity and Epilepsy: a Review. Raven Press, New York, 1979 .

16. Radovicci A - Enilepsie reflexe provoquée par excitations optiques des rayons solaires. Rev Neurol 1:305, 1932.

17. Reilly E, Peters JK - Relationship of some varieties of electroencephalographic photosensitivity to clinical convulsive disorders. Neurology 23:1040, 1973.

18. Stephansson SB, Darby CE, Wilking AJ, Binnie CD, Marlton AP, Smith AT, Stockley AV - Television epilepsy and pattern sensitivity. Br Med $J$ 2:88, 1977.

19. Takahashi $\mathbf{T}$ - Activation methods. In Niedermeier $\mathbf{E}$, Silva FL (eds): Electroencephalography. Urban \& Schwarzenberg, Baltimore, 1982.

20. Wilkins AJ, Darby CE, Binnie CD - Neurophysiological aspects of pattern-sensitive epilepsy. Brain 102:1, 1979.

21. Wilkins AJ, Darby CE, Binnie CD, Stefansson SB, Jeavons PM, Harding GFA Television epilepsy: the role of pattern. Electroenceph Clin Neurophysiol 47:163, 1979. 